\title{
Transgender Experience of Mental Healthcare in Australia
}

\author{
Laura M. Halliday, Nerina J. Caltabiano \\ Department of Psychology, College of Healthcare Sciences, James Cook University, Cairns, Australia \\ Email: Nerina.Caltabiano@jcu.edu.au
}

How to cite this paper: Halliday, L. M., \& Caltabiano, N. J. (2020). Transgender Experience of Mental Healthcare in Australia. Psychology, 11, 157-172.

https://doi.org/10.4236/psych.2020.111011

Received: October 17, 2019

Accepted: January 13, 2020

Published: January 16, 2020

Copyright $\odot 2020$ by author(s) and Scientific Research Publishing Inc. This work is licensed under the Creative Commons Attribution International License (CC BY 4.0).

http://creativecommons.org/licenses/by/4.0/

\begin{abstract}
Emerging global research suggests that transgender people experience poorer physical and mental health outcomes, as well as higher rates of discrimination in healthcare settings. To explore this in an Australian context, a qualitative research project was undertaken to explore the helpful and unhelpful therapy experiences of six transgender Australians. Using interpretative phenomenological analysis, four master themes emerged from the interview data, two of which are explored in depth. The research brings valuable insight into working towards positive outcomes with transgender clients with suggestions for changes in clinical practice for mental healthcare providers, education, training and future research.
\end{abstract}

\section{Keywords}

Transgender Clients, Australia, Qualitative Research, Transgender Mental Health, LGBTIQ+

\section{Introduction}

Transgender individuals are facing multiple forms of personal and systematic discrimination in Australia. Taking into consideration that this growing population experience higher levels of mental health issues due to minority stress, and are required to have frequent interactions with mental health providers, it is important to ensure that psychological services provided are inclusive, welcoming and have positive therapeutic outcomes.

This qualitative study examines the experiences of therapy for transgender Australians. The aims of the current study are: 1) To listen to, and accurately reflect, the helpful and unhelpful experiences of therapy from the unique perspective of transgender Australians residing outside metropolitan centres; and 2) To use this preliminary research to provide suggestions for improving psychological 
services in an Australian context.

\section{Literature Review}

For the purpose of this study, the word "transgender" is used as an umbrella term to describe a number of diverse and distinct gender identities including transgender people, non-binary people, gender nonconforming people, transsexual people, androgynous persons, intersex persons, bi-gendered, genderfluid, sistagirls, brotherboys and gender queer persons (Couch et al., 2007; Dean et al., 2000; Gainor, 2000; Kuper, Nussbaum, \& Mustanski, 2012). “Therapy” was defined as one-on-one professional therapeutic encounters with professionals in the mental healthcare industry. Helpful and unhelpful interview responses referred to therapeutic encounters with counsellors, psychologists and psychiatrists.

The last decade has seen gender identity in the media spotlight with a vast increase in visibility of transgender people (Hendricks \& Testa, 2012). Concurrently, global academic research has begun to unveil a disturbing pattern of high rates of discrimination, injustice, and physical and mental health issues experienced by this vulnerable minority population. Early research on transgender individuals interpreted variance in gender identity to be a representation of "insanity” (Krafft-Ebing, 1965) or underlying pathology (Haraldsen \& Dahl, 2000). However, more recently, there has been an increased understanding that higher rates of mental health issues in this population are not a reflection of an inherent pathology but rather social discrimination. Research indicates that the dysphoria experienced by transgender individuals is derived more from a conflict between the individual and society rather than an individual's mental health (Bartlett, Vasey, \& Bukowski, 2000). Recent views of transgender issues in healthcare have become more progressive, shifting from a reflection of pathology to one of a valid gender identity (Dean et al., 2000).

Research on sexuality and gender has historically been examined by researching the LGBTIQ+ (Lesbian, Gay, Bisexual, Transgender, Intersex and Queer) community as a whole. However, as growing numbers of people identify as transgender it has become increasingly evident that this is a unique population. Emerging research suggests that transgender people report higher levels of suicide attempts, poorer mental health outcomes, and higher rates of discrimination, harassment and violence when compared to cisgender populations in the LGB community (Bockting, Huang, Ding, Robinson, \& Rosser, 2005; Couch et al., 2007; Leonard et al., 2012; Mathy, 2003; Mathy, Lehmann, \& Kerr, 2004). Furthermore, transgender individuals are unique in that they sometimes require: clinicians with appropriate knowledge to make relevant decisions in a gatekeeper role, and who have explored their own reaction to non-traditional gender identities; and coordination of multiple types of services (e.g. medical, legal, financial) (Israel, Gorcheva, Burnes, \& Walther, 2008). A therapist who understands experiences and issues related to transgender people can provide transgender clients with more effective treatment (Grossman, D’Augelli, Howell, \& Hubbard, 2005). 
Despite this, there is a paucity of studies that aim to improve mental healthcare provided to transgender individuals. Although few, studies of transgender mental health status in Australia do exist (Boza \& Nicholson Perry, 2014; Couch, Pitts, Croy, Mulcare, \& Mitchell, 2008; Couch et al., 2007; Leonard et al., 2012; Pitts, Couch, Croy, Mitchell, \& Mulcare, 2009; Pitts, Couch, Mulcare, Croy, \& Mitchell, 2009; Riggs, Coleman, \& Due, 2014), as well as progressive research on evidence-based models for understanding mental health experiences of transgender Australians (Riggs, Ansara, \& Treharne, 2015). Although sparse, these studies appear to align with international research of transgender populations, indicating that transgender individuals have poorer mental health outcomes compared to the overall population and that a clear relationship exists between experiences of discrimination and poor mental health (e.g. Grant et al., 2011; McNeil, Bailey, Ellis, Morton, \& Regan, 2012; Riggs, Ansara, \& Treharne, 2015; Rotondi et al., 2012).

As well as experiencing physical and emotional discrimination, transgender people experience various forms of broader systematic discrimination in the form of inequalities in the areas of housing, employment, education, and in the healthcare system (Boza \& Nicholson Perry, 2014; Couch et al., 2007; Dean et al., 2000; Gainor, 2000; Leonard et al., 2012). For transgender people, health issues associated with gender and transitioning are multi-faceted and can be complex and/or difficult. Troublingly, research suggests that transgender people commonly experience victimisation in the area of healthcare service provision (Couch et al., 2007; Grant et al., 2011; Lombardi, Wilchins, Priesing, \& Malouf, 2002). An Australian study in 2012 found that $68.6 \%$ of respondents reported at least one instance of gender-related victimization in general, with over a quarter of the sample participants (25.1\%) reporting discrimination from healthcare services (Leonard, 2012). Discrimination can impact health-seeking behaviours. Transgender clients have reported a delay when seeking treatment due to the expectation that they will be subject to discrimination or receive reduced quality of care (Heck, Sell, \& Gorin, 2006; Mayer et al., 2008). There is a continuing need for transgender sensitivity training to ensure individual healthcare workers and agencies are able to provide quality and inclusive services.

With respect specifically to psychological services, qualitative studies examining how to improve the quality of psychological support to transgender individuals are limited globally. Studies that do examine improvements to the psychological support tend to focus on the LGBTIQ+ community as a whole (Israel, Gorcheva, Burnes et al., 2008; Victor \& Nel, 2016) and/or examine the perspective of treatment providers (Barrett \& McWhirter, 2002; Bowers \& Bieschke, 2005; Israel, Gorcheva, Walther, Sulzner, \& Cohen, 2008). A few qualitative studies examining transgender mental healthcare service provision are beginning to be reported in the United States of America and the United Kingdom (Applegarth \& Nuttall, 2016; Benson, 2013; Bess \& Stabb, 2009; Sperber, Landers, \& Lawrence, 2005). These studies report on the individual perspectives of transgender 
clients, detailing examples of low-quality healthcare service where they have been met with ignorance, insensitivity and discrimination, as well as participants describing supportive and affirming relationships with their therapists leading to positive therapeutic outcomes. Although these studies examine different individuals in various countries, they do appear to maintain some common themes: firstly provision of treatment for transgender individuals requires specific practitioner knowledge; and secondly an essential element for helpful experiences of therapy is authentic and respectful treatment of the client.

\section{Methods}

\subsection{Participants}

A total of six participants were interviewed as part of the study, all of whom identified as transgender. Participants came from a diverse background of gender variance including those who identified as gender queer, gender fluid, transitioning and non-binary (see Table 1).

Three of six participants identified as female or male (who had been assigned the opposite gender binary at birth), while the other three identified as a gender somewhere in between the binary of male and female. At the time of the study all participants lived in Far North Queensland (Cairns or Townsville) and had done so for the last five years. All reported their ethnicity as European Australian. At the time of the interviews participants ranged in age from 22 to $69(M=33.5)$.

All participants had engaged in counselling at some point in the past five years. Therapeutic support from other professions (other than counsellors, psychologists or psychiatrists) was acceptable for the study but not reported by participants. All participants had received therapy through gender-identity specialist services at some stage. Helpful and unhelpful situations were described from therapeutic sessions in both privately or publically funded organisations.

\subsection{Procedure}

Ethical approval for the project was obtained from the Human Research Ethics Committee of James Cook University (Approval Number H6320). Participants were recruited using snowball sampling. No participants were excluded from the study as all met the criteria of defining themselves as transgender, were living in

Table 1. Brief details of the participants.

\begin{tabular}{ccccc}
\hline Pseudonym & Personal gender identity & Preferred Pronoun & Age & Sexual identity \\
\hline Riley & Non-binary & Any & 28 & Queer \\
Charlie & Non-binary & They/she & 25 & Pansexual \\
River & Non-binary & They/he & 31 & N/A \\
Milan & Female & She & 69 & Straight \\
Jamie & Male & He & 25 & Straight \\
Sage & Female & She/her/they & 23 & Not straight \\
\hline
\end{tabular}


Far North Queensland, and had experience with counselling/psychotherapy.

All participants were offered an information sheet ensuring that there was a confidential way of communicating (via email) and all participants were fully briefed on the research. Further information on the study, including the proposed interview questions were offered to all participants prior to the interviews (see Table 2). The participants were asked to consent to an interview that was recorded and transcribed. All names have been changed to protect the privacy of the participants.

\section{Results}

Two master themes, use of language and knowledge of transgender issues, are explored here with respect to the subthemes of helpful and unhelpful therapy experiences.

\subsection{Use of Language}

The way in which we speak to those around us, the language we choose to use, is an indication of our respect or disrespect for them and the lives they lead. This is particularly true when speaking to people who are in minorities that experience stigma and discrimination. The words and phrases that therapists used in-session were a crucial decider between a participant reporting a session as helpful, creating therapeutic alliance and therapy outcomes, or unhelpful, leading to the termination of sessions and occasionally damaging the clients' sense of self-acceptance.

Table 2. Interview questions offered to participants prior to the interview.

Interview Questions

1) Can you think of one situation in your session that was particularly helpful/unhelpful?

If yes:

- Can you describe the therapist in terms of professional training?

- Was gender identity mostly what you dealt with, or were there other issues you addressed in therapy?

- Can you describe what the main aspects of the situation were that made the experience helpful/unhelpful for you?

- Did you find any of the language used in the therapeutic situation inclusive? If so, can you give me a specific example?

- Were there any specific behaviours that occurred in the therapeutic situation that put you at ease and made it comfortable for you to continue with the session? If so, can you tell me about them?

- How did the helpful/unhelpful situation affect your therapy outcomes?

- How do you think this situation affected your connection and trust of the therapist?

- Do you think the gender identity or sexuality of the therapist is important?

2) Do you have an opinion on how a therapist should address the gender identity of a client when it is not the client's presenting concern?

3) Can you identify any barriers or encouragements to help seeking (e.g. the structure of the mental health system or the environment of the therapy setting)?

4) Do you have anything else you wanted to add about how mental health care professionals, or the mental health system, can support people who are trans/non binary? 


\subsubsection{Helpful}

All participants mentioned the use of language as a powerful influence on how helpful a session was for them; how it could increase rapport with the therapist and benefit therapeutic outcomes for themselves. Charlie and Jamie mentioned the use of inclusive language in the context of using congruent language. This included using language that the interviewee could understand ("layman's terms") or colloquialisms. However, all interviewees mentioned the positive outcomes from correct use of personal pronouns, increasing how helpful and effective a session was for them. The use of pronouns in the discussion that follows reflects the preferences of the participants e.g., the plural pronoun "their" or "them" is used.

As someone who identifies as non-binary, Charlie found their counsellor (despite having no previous experience with transgender clients) was able to help their understanding of their own gender by being open and flexible with use of pronouns:

He just kept it neutral. I am so fluid, it's like ... it wouldn't help if he tried to set something in stone anyway about who I am and how to refer to me because I would come in the next day and I would probably be different again.

-Charlie

In this helpful situation the counsellor also avoided making potentially damaging heteronormative assumptions about the gender of Charlie's partners. Charlie's counsellor used words like "partner" instead of using gendered language such as "boyfriend" or "girlfriend". Charlie found this appropriate use of language established rapport and trust, helping them to talk openly together. Charlie felt respected and heard in their sessions.

One difficult situation with respect to language use can be the appropriate use of pronoun when referring to a client's past, when they were presenting as the gender assigned to them at birth. Riley described a helpful situation where their therapist skillfully navigated past genders by using neutral gender language:

I think he was cautious around pronouns even in me referring to my history and stuff like that. He would pull into third person to kind of take me through a situation I was describing. He would do that quite deliberately and carefully so as not to gender it.

$$
\text { -Riley }
$$

The privacy of a session is not the only place where appropriate language use is important. The front desk of a clinic is a public setting, and interviewees frequently noted this as a place of potential anxiety, and possibly being misgendered. River found that the staff at the front desk in clinics who had gender-diverse clients knew how to ask about pronouns respectfully, making file notes of correct name and pronoun. This created a safer space for River to attend sessions. 
Use of language can be a powerful tool for creating helpful situations communicating respect and safety to a client. Unsurprisingly, unhelpful situations were often described by interviewees as those with disrespectful use of language.

\subsubsection{Unhelpful}

Language use was also an area that created unhelpful scenarios, both subtle and palpable, influencing how comfortable participants felt in the session, often breaking rapport with their therapist. This is particularly important as participants felt that language could alienate them from their therapist and themselves, if used offensively.

In the previous helpful situation, River described inclusive language use at the front desk of a gender clinic. However, they also described administration forms at other clinics that were binary and therefore unhelpful. Forms with only two gender options made interviewees, including River, feel excluded and unwanted.

That first place had a form that you filled out on the way in and it only had male and female. Actually... all of the other clinics I went to only had male or female options.

Forms at the front desk of a clinic are clearly an important issue for interviewees. Riley described an unhelpful situation where the forms to complete at a gender clinic were confusing and confronting for someone who was only beginning their gender identity journey.

The first thing she presented me with was a slip of paper and it was for me to mark out my details in terms of what's your preferred name, your preferred gender. It was kind of like a tick box thing where it had, like, 24 options... I was overwhelmed... the way that she presented it, it was like 'I can't even talk to you really, until you've done this'... I was like... "if I tick a different box do I get a different treatment?" They just wanted to feel safely that they wouldn't offend me.

Riley's situation reflects a genuine attempt to be inclusive unintentionally creating an unhelpful situation. All interviewees reported that a simple acknowledgement of the unintentional error-an apology — was enough to mend any simple offensive language use. Fortunately, out-right examples of offensive behaviour were rarely reported in unhelpful situations. Those that were, often included language use that was inappropriate and offensive, damaging the rapport with the therapist and immediately ending the session. One example of this was reported by River:

I went to another clinic that was probably the worst ... in one session she stopped the conversation and said "wait, wait, wait ... are you a HOMOSEXUAL?" [River laughs] And I was like...shocked by it. I was like ... wow I can't get very deep with you ... how do I even fucking answer that ques- 
tion as a non-binary trans person?

Diagnosis is another way in which language can be used in a helpful or unhelpful context. It is a hotly contested issue with respect to gender identities, with the power to pathologise or support a client's gender. Milan experienced a damaging situation where the unhelpful language use was a label from a psychiatrist she was seeing for a single session:

My unhelpful one was the first psychiatrist I saw [where it] was an assessment to determine if I was "really" trans or not... I was out at work [as transgender]. My ID was changed. My presentation was changed. My name was changed... the outcome of the assessment was that I was a transvestite fetishist! It was pathologising. That fucking pisses us off... it was condescending. It was judgemental. It was predetermined. There was no space for the person presenting to actually explain themselves. It was a check box! Do you tick this box? No, no, no!

-Milan

Milan sought a second opinion after this session and was supported by a psychiatrist whose helpful behaviour and language created a safe therapeutic alliance. She currently lives a happy life as her genuine gender. However, this unhelpful situation was clearly a painful memory, leaving lasting damage to her sense of self and her trust of therapists.

\subsubsection{Summary}

The master theme use of language highlighted examples of discrimination or pathologising language that is clearly unethical and should be avoided. Blatant discrimination was also reported in previous research from various countries, indicating that discrimination is commonly experienced in therapy (Applegarth \& Nuttall, 2016; Benson, 2013; Bess \& Stabb, 2009; Sperber et al., 2005). To avoid these critical errors therapists should interrogate their own views on non-traditional gender identities to anticipate how they would respond to a client who identifies as transgender. A therapist can refer a client to another therapist if they believe support for the individual is outside of their competencies. However, in rural and remote areas, with few people providing support, this may not be an option. It is important to note that the general consensus was that any unintentional mistakes, such as misgendering a client, could be easily rectified with an authentic apology. Participants in this study were aware that therapists may not be versed in correct pronoun use and that this is a skill that can take time to learn efficiently.

\subsection{Knowledge of Transgender Issues}

Each person is a unique combination of their lived experience that can include family culture, gender, age, race, nationality and more. Therefore, it is important for therapists to be able to balance between having some understanding of 
common issues or experiences that people might face as a part of a minority while keeping in mind that they are individuals. Knowledge of transgender issues was often described by interviewees as helpful and at other times unhelpful. What appeared to make the distinction was how that knowledge was utilised.

\subsubsection{Helpful}

A common theme for participants was a preference for therapists who had previous experience with transgender clients or the wider LGBTIQ+ community.

So ... it's that training. It's that background. That knowledge that really helps.

$$
\text { -Jamie }
$$

In general, helpful situations were highlighted by therapists with knowledge of transgender issues. These therapists were less likely to use offensive language, ask inappropriate questions, or contribute all psychological issues to gender. Importantly, multiple interviewees highlighted that this did not mean the practitioner themselves had to be a part of the LGBTIQ+ community.

I would hate the thought that you could only seek out queer psychs or queer people because you're demeaning the profession to say you can only have credible psychotherapy from somebody who is just like me.

Riley found sessions were helpful when the psychiatrist had an in-depth knowledge of Gender Dysphoria assessment, diagnosis and intervention. This was particularly helpful as he also had an understanding of the complex and, at times, arbitrary nature of this process. Riley found that this session was helpful as it created space for an in-depth discussion that empowered them by increasing their understanding of the system and their own gender identity:

He did a prologue at the beginning in terms of, you know, this is something that he has worked in before and we're here to kind of talk about what is actually affecting you not whether or not it's valid ... it was back when the DSM IV was still GID [Gender Identity Disorder] and they were going to change it to Gender Dysphoria ... he explained the history of the DSM and the role of himself as a gate [keeper] ... he explained it was just an arbitrary kind of thing.

$$
\text { -Riley }
$$

Although having a good understanding of transgender issues was an important factor to interviewees, it became clear that it was not having the knowledge itself but how the therapist integrated that information into the session that created a helpful or unhelpful situation. Having a rigid understanding of transgender issues and trying to fit people into that mould was unhelpful and will be explored in the next section. On the contrary, having no knowledge could manifest as a supporting and helpful session using open-minded honesty and a wil- 
lingness to learn about these issues.

Charlie described a helpful situation with a counsellor who openly discussed with them that he had no previous experience with transgender clients or in his personal life. However, Charlie found that the counsellor's open-minded attitude to Charlie's gender created a supportive environment:

A good adaptable way to do things is good because the world is constantly changing and even current standards are going to be different in ten years... I think that [knowledge of transgender issues] is really, really helpful but I think they [therapists] don't need to constantly feel like they need to know everything and that anything new that comes up is, like, terrifying. It's about being adaptable but also finding out the knowledge.

-Charlie

Similarly, River specifically sought out therapists with transgender experience. However, they also acknowledged that each person is an individual with their own story to tell and openness to gender identity is more important than knowledge.

We don't know anything about everyone's experience, whether it is cultural, race or gender. And so it is good to approach this stuff with a really open 'I don't know about that, but that's ok.

-River

All interviewees spoke about wanting to feel safe to explore themselves and connect emotionally to their therapists. Knowledge and experience with transgender clients was helpful for them, but more importantly, it was a willingness to understand them as an individual which was the defining feature for a helpful situation.

\subsubsection{Unhelpful}

Interviewees revealed two primary ways in which therapists could be unhelpful in-session with respect to transgender knowledge. Firstly, they could be ignorant about particular issues, leading to offensive behaviour, or secondly, by being rigid around their understanding of what a transgender person "should" or "should not" be.

Rural and remote areas create difficulties for practitioners to provide appropriate services in many areas of healthcare. Finding a therapist with transgender knowledge was no exception for interviewees in this study. Jamie described the long wait lists for appropriate therapists and discussed an unhelpful experience of having to spend time in therapy explaining basic concepts and issues, taking time away from their own therapy goals:

How can you help someone who doesn't know about it [transgender issues]. I mean you go to some [therapists] and you've got to do the explaining. And they just look at you like 'huh?' 
The other, less intuitive way of being unhelpful was when therapists had a rigid application of transgender assessment and diagnosis. Milan previously mentioned her extremely unhelpful experience of being diagnosed as a "transvestite fetishist", as opposed to having gender dysphoria. Her sadness at the loss of her years where she could have potentially lived an authentic life was diagnosed as a fetish because she did not fit into the criteria that was specified by that psychiatrist.

And there was, in his whole interview, he was an absolute classic formula check list interview technique...his questions were all pre-set and there was no space for me to interject my own voice. I felt absolutely negated.

-Milan

Charlie's unhelpful situation was also with a psychiatrist with many years of experience with transgender clients. Charlie explained to their psychiatrist that they were non-binary and weren't transitioning from one gender to another but were happy to exist as in between. The psychiatrist, who had extensive experience with clients transitioning from one gender to another, struggled to know how to support Charlie.

It just kind of felt like as soon as I said I don't feel like it [was necessary to transition] there was, like, a wall. And he didn't know how to respond to me as someone that wasn't going down that regular path...l felt like I wasn't valid because I didn't feel like transitioning.

-Charlie

This inability to understand a non-binary gender ended the therapeutic relationship but also put pressure on Charlie to consider transitioning to a binary gender. Charlie pondered on the idea that if they had been younger and more impressionable they may have transitioned, which they know now would have been damaging long term.

\subsubsection{Summary}

The second major theme, knowledge of transgender issues, highlighted the importance of therapists having a basic understanding of the discrimination and challenges transgender clients face in order to provide effective support. All participants in the current study called for more training on the basic understanding of minority stress, which includes a greater understanding of all LGBTIQ+ issues, to be included in undergraduate and postgraduate university courses. This call for further training and research was strongly mirrored from qualitative research from North American populations (Bess \& Stabb, 2009; Sperber et al., 2005). This being said, an important result from this study was that participants also had helpful experiences with therapists who had no knowledge of transgender issues or alternatively unhelpful experiences with psychiatrists with years of experience. It was not the level of knowledge or experience that a person has with transgender clients that creates a helpful session but how the therapist uses 
that information to perceive and support their client. Although it is helpful to know about what discrimination a person may have experienced as a particular minority, each individual comes with their own unique story. This does not mean that having a basic understanding of transgender issues is not important but being flexible and open minded is the key feature of a helpful session and ethical practice.

\section{Discussion}

The first aim of the current study was to listen to, and accurately reflect, the helpful and unhelpful experiences of therapy from the unique perspective of transgender Australians. Current findings are congruent with international qualitative research (Applegarth \& Nuttall, 2016; Benson, 2013; Bess \& Stabb, 2009; Sperber et al., 2005) clearly showing that Australian transgender clients experience both discrimination, insensitivity and ignorance as well as affirming and supportive relationships during therapy. Clients who experienced helpful situations described building therapeutic alliances with their therapists leading to positive outcomes in therapy and personal growth. This supports previous findings that therapists who understand the experiences and issues of transgender people can provide transgender clients with more effective treatment (Bess \& Stabb, 2009; Grossman et al., 2005). Meanwhile, unhelpful situations prematurely terminated therapy and frequently caused distress, anger and self-doubt, supporting previous research indicating that transgender clients in Australia are experiencing gender-related victimisation from healthcare services (Leonard et al., 2012).

The second aim of the current study was to use this preliminary research to provide suggestions for improving psychological services in an Australian context. The first major theme, use of language, highlights the importance of inclusive and respectful language in both written and spoken form. This is especially true for minority groups, who are regularly discriminated against, when they seek emotional support in therapeutic settings. Results from the current study clearly indicated that therapists should take care to use language that accurately reflects the name and gender of their client, as well as being careful not to make heteronormative assumptions about their partners or lives.

Administration forms at front desks should be amended to be inclusive but not overwhelming. Both being absent from a form (only have female or male as choices for a person's gender) or being overwhelmed by options may be distressing for people who are seeking help for the first time or are uncertain of their gender. A choice between "male", "female", and "other" appeared to be the general consensus for gold standard of practice. Alternatively, wherever possible, gender can be removed from the forms altogether, deemphasising the importance of gender as a defining aspect of self-identity.

\section{Conclusion}

The aim of the current study was to examine the unique stories of a small sample 
of transgender Australian individuals. Therefore, opinions and outcomes are not representative of all transgender Australians. The participants lived in rural and remote areas of Australia and may reflect a different story from those who live in metropolitan areas. Furthermore, the unique perspectives of individuals who are going through adolescence at present, at a time of rapid change in gender identity, are not included in this study. There is a significant need for further research into the stories of Australian transgender clients from a broad range of demographics that were not able to be captured in this study. Further research is recommended looking at a wider range of individuals, including various cultures, ages, and genders of transgender Australians.

The results of this study identified two ways in which we can improve service provision to transgender clients. One, through inclusive and appropriate language and two, by having a reasonable understanding of transgender issues while simultaneously being open to the continuous changes occurring in our culture with relation to gender identities. Overall the interviews in this research echoed the underlying message in previous research of helpful or unhelpful situations in therapy for the LGBT community by Israel, Gorcheva, Burnes et al. (2008): irrespective of gender or sexual identity all clients deserve to be treated with respect, honesty and kindness. The inherent damage people have from discrimination and bigotry are the reasons that people seek therapy. These should not occur within the sessions themselves. Mental healthcare professionals should create support for their clients that are safe and caring, regardless of personal beliefs.

\section{Acknowledgements}

We would like to acknowledge the grant provided by the Far North Queensland Hospital Foundation.

\section{Conflicts of Interest}

The authors declare no conflicts of interest regarding the publication of this paper.

\section{References}

Applegarth, G., \& Nuttall, J. (2016). The Lived Experience of Transgender People of Talking Therapies. International Journal of Transgenderism, 17, 66-72. https://doi.org/10.1080/15532739.2016.1149540

Barrett, K. A., \& McWhirter, B. T. (2002). Counselor Trainees Perceptions of Clients Based on Client Sexual Orientation. Counselor Education and Supervision, 41, 219. https://doi.org/10.1002/j.1556-6978.2002.tb01285.x

Bartlett, N. H., Vasey, P. L., \& Bukowski, W. M. (2000). Is Gender Identity Disorder in Children a Mental Disorder? Sex Roles, 43, 753-785. https://doi.org/10.1023/A:1011004431889

Benson, K. E. (2013). Seeking Support: Transgender Client Experiences with Mental Health Services. Journal of Feminist Family Therapy, 25, 17-40. https://doi.org/10.1080/08952833.2013.755081 
Bess, J., \& Stabb, S. (2009). The Experiences of Transgendered Persons in Psychotherapy: Voices and Recommendations. Journal of Mental Health Counseling, 31, 264-282. https://doi.org/10.17744/mehc.31.3.f624154681133w50

Bockting, W., Huang, C.-Y., Ding, H., Robinson, B. B., \& Rosser, B. S. (2005). Are Transgender Persons at Higher Risk for HIV than Other Sexual Minorities? A Comparison of HIV Prevalence and Risks. International Journal of Transgenderism, 8, 123-131. https://doi.org/10.1300/J485v08n02_11

Bowers, A., \& Bieschke, K. J. (2005). Psychologists' Clinical Evaluations and Attitudes: An Examination of the Influence of Gender and Sexual Orientation. Professional Psychology: Research and Practice, 36, 97-103. https://doi.org/10.1037/0735-7028.36.1.97

Boza, C., \& Nicholson Perry, K. (2014). Gender-Related Victimization, Perceived Social Support, and Predictors of Depression among Transgender Australians. International Journal of Transgenderism, 15, 35-52. https://doi.org/10.1080/15532739.2014.890558

Couch, M. A., Pitts, M. K., Patel, S., Mitchell, A. E., Mulcare, H., \& Croy, S. L. (2007). TranZnation: A Report on the Health and Wellbeing of Transgender People in Australia and New Zealand.

Couch, M. A., Pitts, M., Croy, S., Mulcare, H., \& Mitchell, A. (2008). Transgender People and the Amendment of Formal Documentation: Matters of Recognition and Citizenship. Health Sociology Review, 17, 280-289. https://doi.org/10.5172/hesr.451.17.3.280

Dean, L., Meyer, I. H., Robinson, K., Sell, R. L., Sember, R., Silenzio, V. M., White, J. et al. (2000). Lesbian, Gay, Bisexual, and Transgender Health: Findings and Concerns. Journal of the Gay and Lesbian Medical Association, 4, 102-151. https://doi.org/10.1023/A:1009573800168

Gainor, K. A. (2000). Including Transgender Issues in Lesbian, Gay and Bisexual Psychology. In B. Greene, \& G. L. Croom (Eds.), Education, Research, and Practice in Lesbian, Gay, Bisexual, and Transgendered Psychology: A Resource Manual (Vol. 5, pp. 131-160). Thousand Oaks, CA: SAGE Publications, Inc. https://doi.org/10.4135/9781452233697.n6

Grant, J. M., Mottet, L., Tanis, J. E., Harrison, J., Herman, J., \& Keisling, M. (2011). Injustice at Every Turn: A Report of the National Transgender Discrimination Survey. Washington DC: National Center for Transgender Equality.

Grossman, A. H., D’Augelli, A. R., Howell, T. J., \& Hubbard, S. (2005). Parent' Reactions to Transgender Youth' Gender Nonconforming Expression and Identity. Journal of Gay \& Lesbian Social Services, 18, 3-16. https://doi.org/10.1300/J041v18n01_02

Haraldsen, I. R., \& Dahl, A. A. (2000). Symptom Profiles of Gender Dysphoric Patients of Transsexual Type Compared to Patients with Personality Disorders and Healthy Adults. Acta Psychiatrica Scandinavica, 102, 276-281. https://doi.org/10.1034/j.1600-0447.2000.102004276.x

Heck, J. E., Sell, R. L., \& Gorin, S. S. (2006). Healthcare Access among Individuals Involved in Same-Sex Relationships. American Journal of Public Health, 96, 1111-1118. https://doi.org/10.2105/AJPH.2005.062661

Hendricks, M. L., \& Testa, R. J. (2012). A Conceptual Framework for Clinical Work with Transgender and Gender Nonconforming Clients: An Adaptation of the Minority Stress Model. Professional Psychology-Research and Practice, 43, 460-467. https://doi.org/10.1037/a0029597

Israel, T., Gorcheva, R., Burnes, T. R., \& Walther, W. A. (2008). Helpful and Unhelpful Therapy Experiences of LGBT Clients. Psychotherapy Research, 18, 294-305. https://doi.org/10.1080/10503300701506920

Israel, T., Gorcheva, R., Walther, W. A., Sulzner, J. M., \& Cohen, J. (2008). Therapists' 
Helpful and Unhelpful Situations with LGBT Clients: An Exploratory Study. Professional Psychology: Research and Practice, 39, 361-368.

https://doi.org/10.1037/0735-7028.39.3.361

Krafft-Ebing, R. (1965). Psychopathia Sexualis: With Especial Reference to Contrary Sexual Instinct. Philadelphia: F. A. Davis Company.

Kuper, L. E., Nussbaum, R., \& Mustanski, B. (2012). Exploring the Diversity of Gender and Sexual Orientation Identities in an Online Sample of Transgender Individuals. Journal of Sex Research, 49, 244-254. https://doi.org/10.1080/00224499.2011.596954

Leonard, W. (2012). Private Lives 2: The Second National Survey on the Health and Wellbeing of Gay, Lesbian, Bisexual and Transgender (GLBT) Australians.

Leonard, W., Pitts, M., Mitchell, A., Lyons, A., Smith, A., Patel, S., \& Barrett, A. (2012). Private Lives 2: The Second National Survey of the Health and Wellbeing of GLBT Australians. Melbourne: Australian Research Centre in Sex, Health and Society, La Trobe University.

Lombardi, E. L., Wilchins, R. A., Priesing, D., \& Malouf, D. (2002). Gender Violence: Transgender Experiences with Violence and Discrimination. Journal of Homosexuality, 42, 89-101. https://doi.org/10.1300/J082v42n01_05

Mathy, R. M. (2003). Transgender Identity and Suicidality in a Nonclinical Sample: Sexual Orientation, Psychiatric History, and Compulsive Behaviors. Journal of Psychology \& Human Sexuality, 14, 47-65. https://doi.org/10.1300/J056v14n04_03

Mathy, R. M., Lehmann, B. A., \& Kerr, D. L. (2004). Bisexual and Transgender Identities in a Nonclinical Sample of North Americans: Suicidal Intent, Behavioral Difficulties, and Mental Health Treatment. Journal of Bisexuality, 3, 93-109.

https://doi.org/10.1300/J159v03n03_07

Mayer, K. H., Bradford, J. B., Makadon, H. J., Stall, R., Goldhammer, H., \& Landers, S. (2008). Sexual and Gender Minority Health: What We Know and What Needs to Be Done. American Journal of Public Health, 98, 989-995. https://doi.org/10.2105/AJPH.2007.127811

McNeil, J., Bailey, L., Ellis, S., Morton, J., \& Regan, M. (2012). Trans Mental Health Study 2012. Edinburgh: Scottish Transgender Alliance.

Pitts, M., Couch, M., Croy, S., Mitchell, A., \& Mulcare, H. (2009). Health Service Use and Experiences of Transgender People: Australian and New Zealand Perspectives. Gay and Lesbian Issues and Psychology Review, 5, 167-176.

Pitts, M., Couch, M., Mulcare, H., Croy, S., \& Mitchell, A. (2009). Transgender People in Australia and New Zealand: Health, Well-Being and Access to Health Services. Feminism \& Psychology, 19, 475-495. https://doi.org/10.1177/0959353509342771

Riggs, D. W., Ansara, G. Y., \& Treharne, G. J. (2015). An Evidence-Based Model for Understanding the Mental Health Experiences of Transgender Australians. Australian Psychologist, 50, 32-39. https://doi.org/10.1111/ap.12088

Riggs, D. W., Coleman, K., \& Due, C. (2014). Healthcare Experiences of Gender Diverse Australians: A Mixed-Methods, Self-Report Survey. BMC Public Health, 14, 230. https://doi.org/10.1186/1471-2458-14-230

Rotondi, N. K., Bauer, G. R., Travers, R., Travers, A., Scanlon, K., \& Kaay, M. (2012). Depression in Male-to-Female Transgender Ontarians: Results from the Trans PULSE Project. Canadian Journal of Community Mental Health, 30, 113-133. https://doi.org/10.7870/cjcmh-2011-0020

Sperber, J., Landers, S., \& Lawrence, S. (2005). Access to Healthcare for Transgendered Persons: Results of a Needs Assessment in Boston. International Journal of Transgen- 
derism, 8, 75-91. https://doi.org/10.1300/J485v08n02_08

Victor, C. J., \& Nel, J. A. (2016). Lesbian, Gay, and Bisexual Clients' Experience with Counselling and Psychotherapy in South Africa: Implications for Affirmative Practice. South African Journal of Psychology, 46, 351-363.

https://doi.org/10.1177/0081246315620774 